\title{
Flow dynamics of Byrd Glacier, East Antarctica
}

\author{
C.J. VAN DER VEEN, ${ }^{1,3}$ L.A. STEARNS,${ }^{2,3}$ J. JOHNSON, ${ }^{4}$ B. CSATHO ${ }^{5}$ \\ ${ }^{1}$ Department of Geography, University of Kansas, Lawrence, KS, USA \\ E-mail: cjvdv@ku.edu \\ ${ }^{2}$ Department of Geology, University of Kansas, Lawrence, KS, USA \\ ${ }^{3}$ Center for Remote Sensing of Ice Sheets, University of Kansas, Lawrence, KS, USA \\ ${ }^{4}$ Department of Computer Sciences, University of Montana, Missoula, MT, USA \\ ${ }^{5}$ Department of Geology, University at Buffalo, Buffalo, NY, USA
}

\begin{abstract}
Force-balance calculations on Byrd Glacier, East Antarctica, reveal large spatial variations in the along-flow component of driving stress with corresponding sticky spots that are stationary over time. On the large scale, flow resistance is partitioned between basal $(\sim 80 \%)$ and lateral $(\sim 20 \%)$ drag. Ice flow is due mostly to basal sliding and concentrated vertical shear in the basal ice layers, indicating the bed is at or close to the pressure-melting temperature. There is a significant component of driving stress in the across-flow direction resulting in nonzero basal drag in that direction. This is an unrealistic result and we propose that there are spatial variations of bed features resulting in small-scale flow disturbances. The grounding line of Byrd Glacier is located in a region where the bed slopes upward. Nevertheless, despite a 10\% increase in ice discharge between December 2005 and February 2007, following drainage of two subglacial lakes in the catchment area, the position of the grounding line has not retreated significantly and the glacier has decelerated since then. During the speed-up event, partitioning of flow resistance did not change, suggesting the increase in velocity was caused by a temporary decrease in basal effective pressure.
\end{abstract}

KEYWORDS: Antarctic glaciology, glacier flow, ice dynamics

\section{INTRODUCTION}

Byrd Glacier, named after Rear Admiral Richard E. Byrd, is the largest of a dozen outlet glaciers draining ice originating on the East Antarctic plateau into the Ross Ice Shelf. Its catchment basin covers an area of $\sim 1070400 \mathrm{~km}^{2}$ and this ice is funneled into a $\sim 20 \mathrm{~km}$ wide and $\sim 100 \mathrm{~km}$ long fjord before diverging onto the ice shelf (Fig. 1). Byrd, as well as other glaciers transecting the Transantarctic Mountains, represents the transition from sheet-style flow in East Antarctica to ice-shelf spreading, but the nature of this transition remains poorly understood. Scofield and others (1991) argue that the glacier bed is frozen and the driving stress is primarily balanced by basal drag. Reusch and Hughes (2003), on the other hand, model the flow transition by introducing a basal buoyancy factor that ranges from 0 in the interior to 1 on a floating ice shelf. Truffer and Echelmeyer (2003) classify Byrd Glacier as an outlet glacier, rather than falling somewhere in the spectrum ranging from ice stream (high speeds and low driving stress, narrow lateral shear margins; e.g. Whillans Ice Stream, West Antarctica) to isbræ (high speeds achieved under high driving stress, wide lateral shear margins; e.g. Jakobshavn Isbræ, West Greenland). By their definition, an outlet glacier drains an ice sheet through a deep bedrock channel.

Byrd Glacier has a comparatively long history of quantitative glaciological investigations, starting with surface-based velocity measurements during the years 1960-62 (Swithinbank, 1963). Seven glaciers draining into the Ross Ice Shelf were surveyed during that campaign. Of these, Byrd was found to be the fastest-moving, with a speed near its center line of $840 \pm 80 \mathrm{~m} \mathrm{a}^{-1}$. Based on the measured velocity transect across the mouth of Byrd Glacier, Swithinbank (1963) estimated an annual discharge of $19 \mathrm{~km}^{3} \mathrm{a}^{-1}$, which is remarkably close to the more recent estimate of $22.32 \pm 1.72 \mathrm{~km}^{3} \mathrm{a}^{-1}$ (Stearns, 2011). Hughes and Fastook (1981) present surface speeds and elevations obtained from ground surveys in 1978-79. Their along-flow velocity profile shows velocity increasing down the fjord, reaching a maximum of $\sim 880 \mathrm{~m} \mathrm{a}^{-1}$ close to where the grounding line was estimated to be located, and slowing down as the ice diverges onto the ice shelf.

In 1978-79, repeat aerial photogrammetry was conducted to measure ice velocity and surface elevation (Brecher, 1982, 1986). These data were used by Whillans and others (1989) to conduct a force-balance assessment, and are also used in the present study. The advent of satellite remote sensing greatly expanded the possibilities of determining ice velocities cost-effectively and without the need for elaborate field campaigns. The first study using Landsat imagery to measure glacier velocity on Byrd Glacier was Lucchitta and Ferguson (1986). By measuring displacements of visible surface features on two images taken nearly 10 years apart, that study found velocities ranging from 750 to $800 \mathrm{~m} \mathrm{a}^{-1}$ on the floating part beyond the grounding line, comparable to earlier studies. Since then, satellite remote sensing has become nearly routine and provided greater temporal coverage of ice velocity (Stearns and others, 2008; Stearns, 2011).

Over the half-century of velocity measurements on Byrd Glacier, no important changes have been observed, with the exception of a comparatively short-lived speed up of $\sim 10 \%$ between December 2005 and February 2007, following drainage of two subglacial lakes in the catchment area (Stearns and others, 2008). Similar drainage events and consequent glacier accelerations may have occurred earlier but gone unnoticed. However, given that deceleration of Byrd Glacier coincided with the termination of the flood and refilling of the lakes by mid-2007, it is not clear what role 


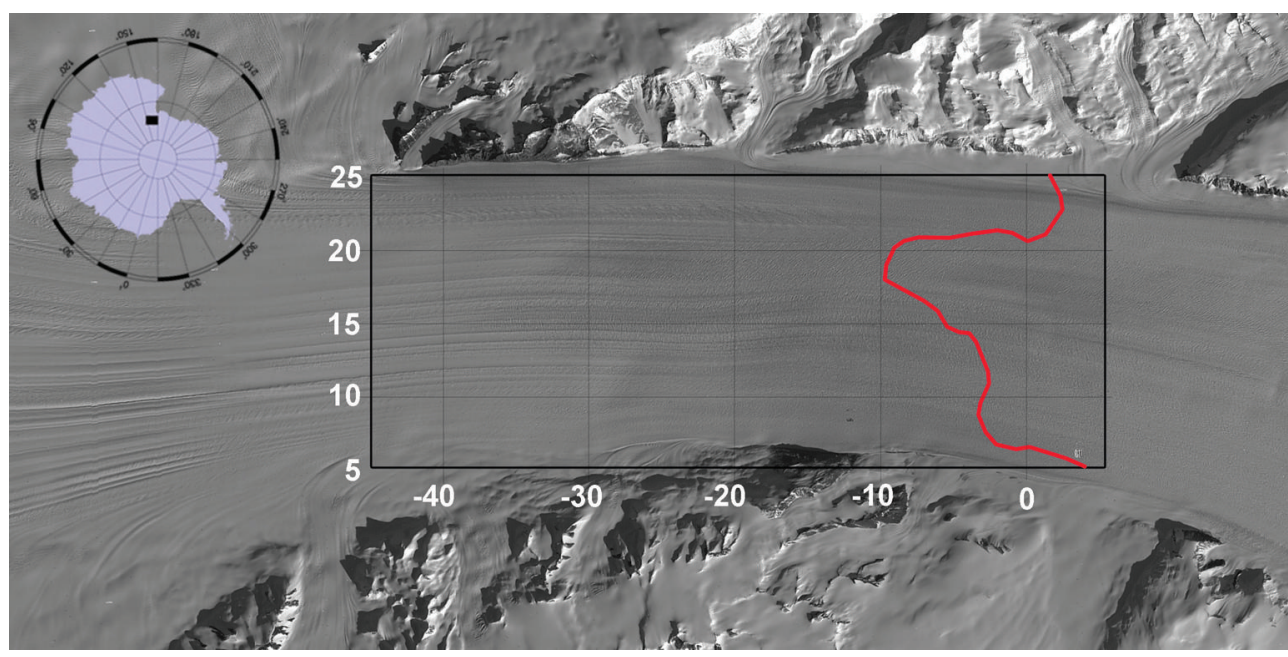

Fig. 1. Location map of the lower trunk of Byrd Glacier. The rectangular box shows the region for which force balance is calculated with labels corresponding to the local coordinates $(\mathrm{km})$. The red line represents the grounding line as determined from flotation. Ice flow is from left to right. The inset map shows the location of Byrd Glacier.

such events play in the overall dynamics and stability of this glacier.

Several previous studies have addressed the dynamics of Byrd Glacier, including the comprehensive map-view assessment of balance of forces on the lower trunk by Whillans and others (1989) and Stearns (2007). Those studies, as well as subsequent studies, were limited by lack of detailed bed topography, relying on a single radarderived profile along the glacier (Mclntyre, 1985).

During the 2011/12 austral summer, the Center for Remote Sensing of Ice Sheets (CReSIS) at the University of Kansas conducted extensive airborne radar sounding for mapping the bed under Byrd Glacier. The resulting bed map allows re-evaluation of results from earlier studies and an investigation into the bed topographic controls on ice flow; this is the primary objective of the present paper. To allow for comparison with the earlier study of Whillans and others (1989), the same velocity and elevation data derived from the late-1970s aerial photogrammetry are initially used to evaluate and interpret the various terms in the balance of forces. A secondary objective is to evaluate temporal changes in the balance of forces and, in particular, whether surface 'waves' identified by Reusch and Hughes (2003) are stationary or migrating along the glacier. For this, time series of velocity and surface elevation are used.

\section{FORCE BALANCE}

The force-balance technique was developed to evaluate forces controlling the flow of glaciers. The steps involved in the calculations are detailed in Whillans and others (1989) and Van der Veen (2013, section 11.2). Below, only a brief summary is given.

In a map-view Cartesian $(x, y)$ coordinate system, balance of forces requires that

$$
\begin{gathered}
\tau_{\mathrm{d} x}=\tau_{\mathrm{bx}}-\frac{\partial}{\partial x}\left(H R_{x x}\right)-\frac{\partial}{\partial y}\left(H R_{x y}\right), \\
\tau_{\mathrm{d} y}=\tau_{\mathrm{by}}-\frac{\partial}{\partial y}\left(H R_{y y}\right)-\frac{\partial}{\partial x}\left(H R_{x y}\right) .
\end{gathered}
$$

The terms on the left-hand sides represent the driving stress, defined as

$$
\begin{aligned}
\tau_{\mathrm{d} x} & =-\rho g H \frac{\partial h}{\partial x}, \\
\tau_{\mathrm{d} y} & =-\rho g H \frac{\partial h}{\partial y},
\end{aligned}
$$

where $\rho$ represents the ice density, $g$ the gravitational acceleration, $H$ the ice thickness, and $h$ the elevation of the upper ice surface. This stress is responsible for making ice flow in the downslope direction and is resisted by drag at the glacier base $\tau_{\mathrm{bx}}, \tau_{\mathrm{by}}$, by gradients in longitudinal stress, and by friction at lateral margins (terms on the right-hand side of Eqns (1) and (2)).

Resistive stresses are calculated from strain rates using Glen's flow law. In the hydrostatic approximation, bridging effects are neglected and the vertical resistive stress, $R_{z z}$, is set to zero. Then

$$
\begin{aligned}
& R_{x x}=B \dot{\varepsilon}_{\mathrm{e}}^{1 /(n-1)}\left(2 \dot{\varepsilon}_{x x}+\dot{\varepsilon}_{y y}\right) \\
& R_{y y}=B \dot{\varepsilon}_{\mathrm{e}}^{1 /(n-1)}\left(\dot{\varepsilon}_{x x}+2 \dot{\varepsilon}_{y y}\right), \\
& R_{x y}=B \dot{\varepsilon}_{\mathrm{e}}^{1 /(n-1)} \dot{\varepsilon}_{x y,}
\end{aligned}
$$

with the strain rates, $\dot{\varepsilon}_{i j}$, obtained from velocity gradients (Van der Veen, 2013, section 3.3). Invoking incompressibility and omitting vertical shear strain rates, the effective strain rate is

$$
\dot{\varepsilon}_{\mathrm{e}}^{2}=\dot{\varepsilon}_{x x}^{2}+\dot{\varepsilon}_{y y}^{2}+\dot{\varepsilon}_{x x} \dot{\varepsilon}_{y y}+\dot{\varepsilon}_{x y}^{2} .
$$

The assumption is made that resistive stresses are constant through the ice thickness, which is tantamount to assuming ice flow is due to basal sliding or that vertical shear is concentrated in the basal ice layers. The value $B=$ $600 \mathrm{kPaa}^{1 / 3}$ is used for the viscosity parameter, corresponding to an ice temperature of $-20^{\circ} \mathrm{C}$. This value is slightly smaller than that used by Whillans and others (1989) and is appropriate for the upper colder and stiffer ice layers.

In previous studies, resistance to flow from gradients in longitudinal stress was defined as

$$
F_{\text {lonx }}=\frac{\partial}{\partial x}\left(H R_{x x}\right)
$$


and lateral drag as

$$
F_{\text {latx }}=\frac{\partial}{\partial y}\left(H R_{x y}\right)
$$

These definitions are somewhat confusing as they imply negative values where these terms provide resistance to flow (as opposed to positive values for basal drag). To be more consistent in the discussion of results, and for ease of interpretation, both terms are defined here as

$$
\begin{aligned}
& F_{\text {lon } x}=-\frac{\partial}{\partial x}\left(H R_{x x}\right), \\
& F_{\text {latx }}=-\frac{\partial}{\partial y}\left(H R_{x y}\right) .
\end{aligned}
$$

Force-balance calculations are performed using data gridded to a $1 \mathrm{~km} \times 1 \mathrm{~km}$ grid with the $x$-axis directed in the approximate direction of ice flow. To minimize errors, spatial gradients are calculated over four grid spacings. Results are presented in a local flow-following coordinate system, defined at each gridpoint by the direction of the velocity vector. Because the geometry of the lower part of Byrd Glacier is relatively simple without important flowline turning, these results are very similar to those in the $(x, y)$ coordinate system (Van der Veen, 2013, section 11.2).

We follow the local coordinate system first used by Brecher (1986) and adopted by Whillans and others (1989). The $x$-axis is horizontal and down-flow, with the origin near the grounding line; the $y$-axis is perpendicular to flow and positive grid-north. Data inputs for velocity, topography and elevation, which were originally in a Universal Transverse Mercator (UTM) projection $\left(57^{\circ} \mathrm{S}\right)$, were rotated $35^{\circ}$ west, with an origin of $80.5^{\circ} \mathrm{S}, 159^{\circ} \mathrm{E}$.

Uncertainties in inferred basal drag can be estimated using the procedure outlined in Van der Veen (2013, section 1.3). While these errors vary spatially, the maximum error is about $\pm 75 \mathrm{kPa}$. For this reason, results for the floating part of the glacier are not discussed here because these errors dominate, with driving stress being small and basal drag zero. Some of the variations on the grounded part may be associated with measurement errors but we are confident that the general pattern is robust and real. Moreover, by considering force budget averaged over the width of the glacier, the error in basal drag is reduced to $\pm 20 \mathrm{kPa}$ or less.

\section{INPUT DATA}

\section{Surface elevation}

In the 1978/79 austral summer, two aerial photogrammetric surveys were conducted over Byrd Glacier with the objective of determining surface elevations and ice displacements. Here we use 810 elevation measurements from the second survey to reconstruct the surface topography shown in Figure 2a. The estimated standard deviation of the gridded elevations is $9 \mathrm{~m}$ (Whillans and others, 1989).

For subsequent epochs, surface elevations are estimated using the rates of elevation change derived by Schenk and others (2005) by comparing 2005 ICESat elevations with the 1978 topographic map from photogrammetry. Assuming these rates also apply to the period 2005-11, elevations at intermediate times (1988, 2006 and 2011) are obtained from linear interpolation.
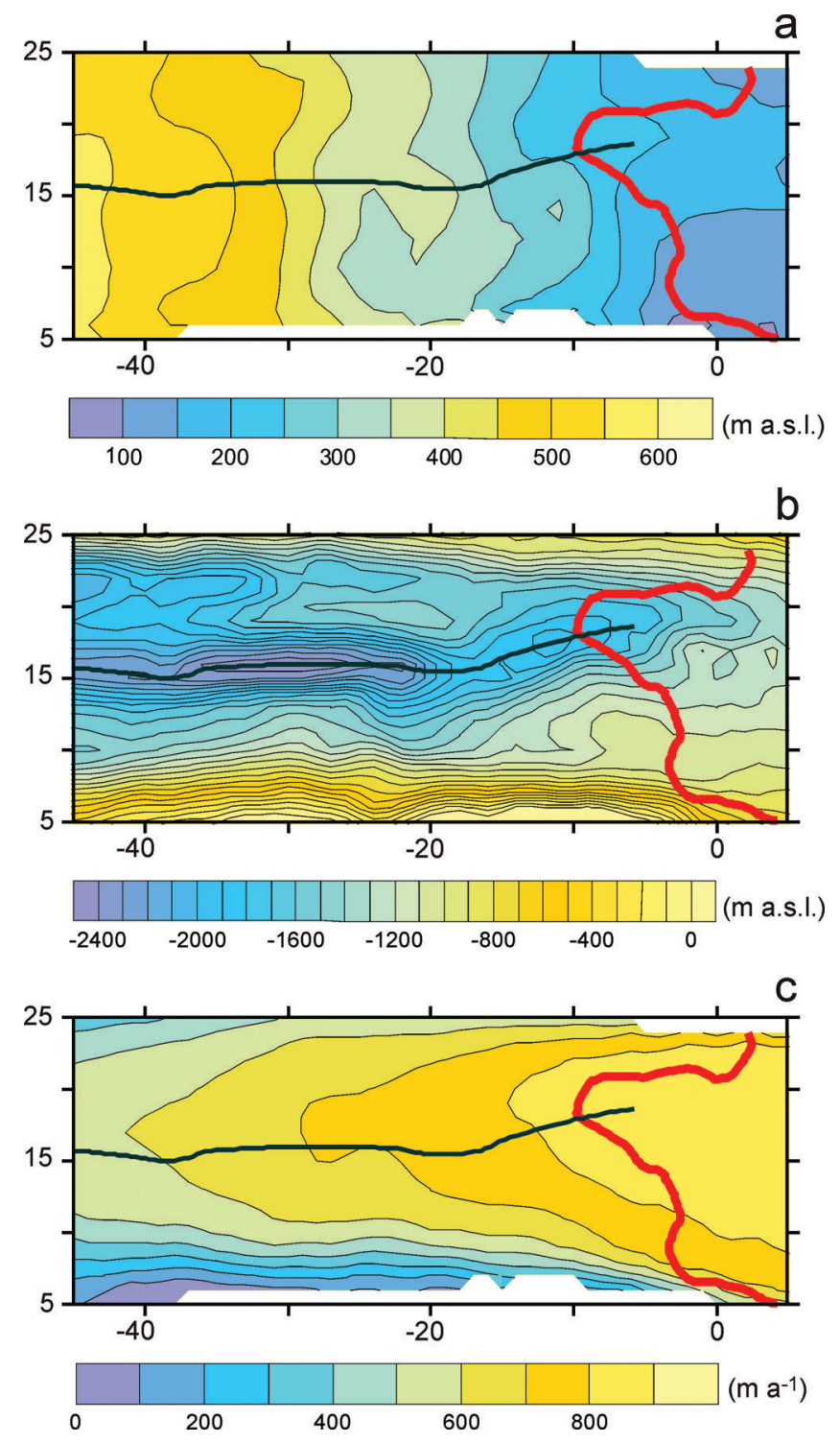

Fig. 2. Surface and bed elevation (standard deviation $9 \mathrm{~m}$ and $50 \mathrm{~m}$ respectively) and surface speed (standard deviation $50 \mathrm{~m} \mathrm{a}^{-1}$ ) on the trunk of Byrd Glacier. The red line across the width of the glacier represents the estimated position of the grounding line based on the flotation criterion. The dark green line is the dynamic center line where the lateral shear stress is zero. Axis labels as in Figure 1.

\section{Bed elevation}

The bed topography used in this study (Fig. 2b) is the gridded bed map produced in early 2013 by CReSIS, based on airborne radar sounding conducted in 2011-12 (Gogineni and others, 2014). The fjord topography is dominated by a deep and relatively narrow trench that becomes shallower towards the grounding line. This trench may have resulted from preferential erosion along the Byrd Glacier discontinuity marking a major crustal-scale boundary in the Byrd depositional basin crossing the Ross Orogen (Stump and others, 2004; Carosi and others, 2007).

From the ice thickness and bed topography, the height above buoyancy can be calculated. The grounding line is defined as the location where this quantity reaches zero, and is shown by the red line in all maps. This position agrees well with that determined by Hughes (1979), Rignot and Jacobs (2002), Brunt and others (2010) and Floricioiu and others (2012). 

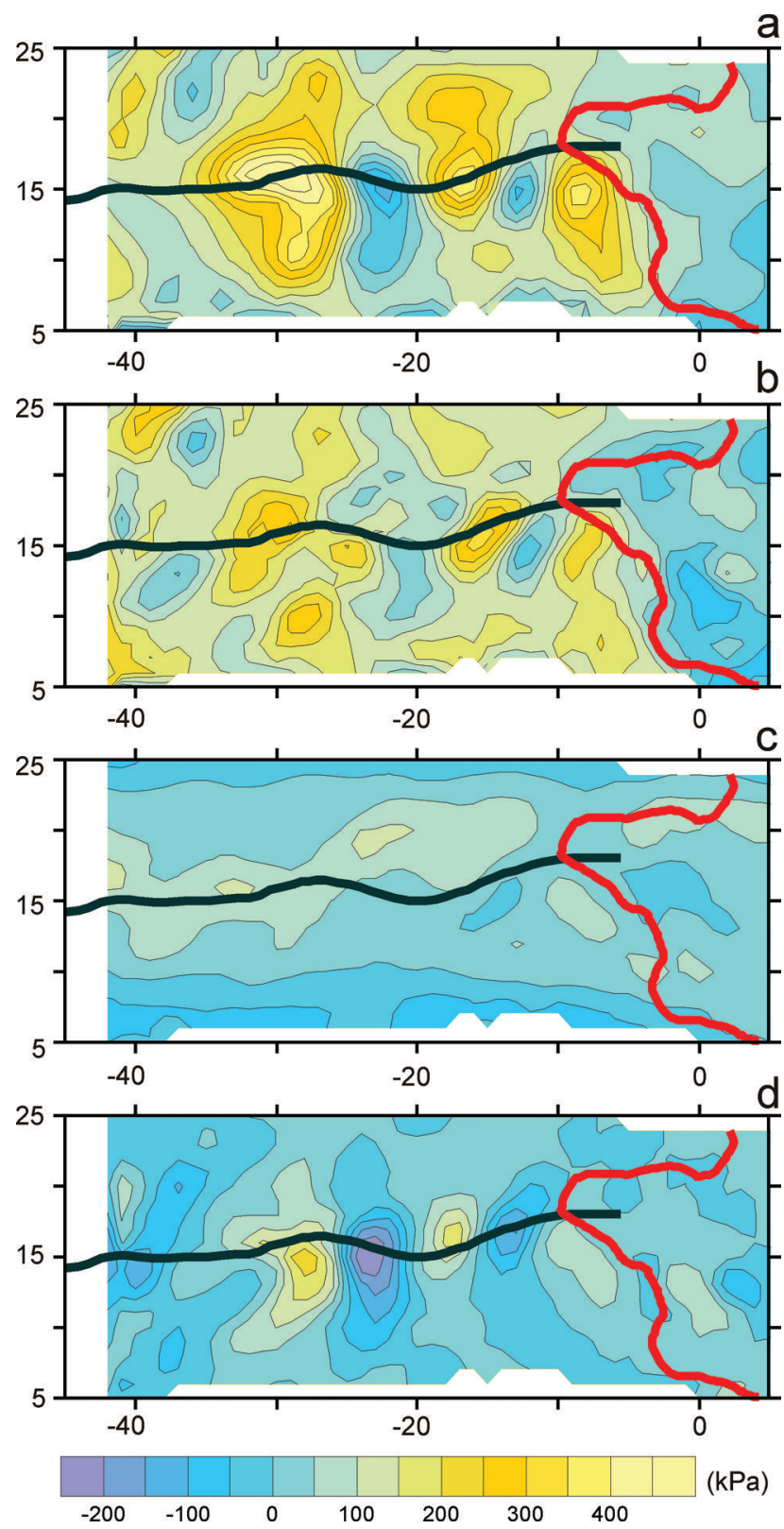

Fig. 3. Terms in the along-flow balance of forces: (a) driving stress, (b) basal drag, (c) lateral drag and (d) gradients in longitudinal stress. Axis labels as in Figure 1.

\section{Surface velocity}

Surface velocities were derived from repeat aerial photogrammetry taken during the 1978/79 austral summer and spaced 56 days apart. Displacements of 601 common points were measured with an accuracy of $\sim 5 \mathrm{~m}$ (Brecher, 1986), giving an estimated velocity error of $50 \mathrm{~m} \mathrm{a}^{-1}$. The magnitude of surface velocity gridded to a $1 \mathrm{~km}$ grid is shown in Figure 2c.

To conduct force-balance assessments for more recent epochs, additional velocities are used from 1988, 2006 and 2011. To obtain ice velocities in 1988 and 2006, we apply a cross-correlation technique (Scambos and others, 1992) to sequential visible images to track the displacement of surface features such as crevasses. Cloud-free, co-registered and orthorectified image pairs are input into the crosscorrelation software, and operator-controlled settings allow for a range of displacement patterns. The technique is described in detail by Stearns and others (2008). In this study, we use Landsat Thematic Mapper (TM) scenes from 22 February 1988 and 8 February 1989; the velocity error for this epoch is $43 \mathrm{ma}^{-1}$. Advanced Spaceborne Thermal Emission and Reflection Radiometer (ASTER) scenes from 5 December 2005 and 28 January 2007 are used to derive velocities for 2006, with an error of $20 \mathrm{~m} \mathrm{a}^{-1}$. Velocities for the 2011 epoch are interferometric synthetic aperture radar (InSAR) velocities with an error of $\sim 6 \mathrm{~m} \mathrm{a}^{-1}$ (Rignot and others, 2011).

The dark green line in all map views represents the dynamic center line defined as where the lateral shear stress is zero. This line closely follows the basal trench but is somewhat displaced from the velocity maxima.

\section{FORCE BALANCE: ALONG-FLOW DIRECTION Basal drag}

Results for the along-flow force-balance terms using the 1978 photogrammetric data are shown in Figure 3. As found by Whillans and others (1989), large variations in driving stress are reduced by gradients in longitudinal stress such that basal drag is spatially less variable. There are isolated regions of high basal drag, most notably in the middle of the glacier at $x=-15 \mathrm{~km}$, upstream of the grounding line. Adjacent to this sticky spot, basal drag becomes slightly negative. However, this negative value falls within the estimated uncertainty of $\pm 75 \mathrm{kPa}$. The spatial pattern in basal drag is explored in more detail below.

\section{Lateral drag}

Flow resistance from lateral drag is greatest near the center of the glacier (Fig. 3c). A similar result was found by Whillans and others (1989) but those authors failed to provide an adequate explanation for this phenomenon. For a bed topography that varies little in the transverse direction, lateral drag would be expected to be equally important across the width of the glacier. However, as revealed by the new bed topography map, there are important variations in bed elevation (and thus in ice thickness) that cause lateral drag to be non-uniform. To investigate this issue in more detail, consider the transect at $x=-20 \mathrm{~km}$.

Figure 4 shows surface and bed elevation across the transect, as well as surface speed from which the lateral shear stress is derived. The shear stress decreases nearly linearly from $+200 \mathrm{kPa}$ at the right margin to $-200 \mathrm{kPa}$ at the opposite margin. Such a linear decrease would be expected if resistance to flow from lateral drag was equally important across the glacier. The width-averaged lateral drag can be estimated from (Van der Veen, 2013, section 4.4)

$$
\bar{F}_{\text {lat }}=-\frac{H(W) R_{x y}(W)-H(-W) R_{x y}(-W)}{2 W},
$$

where $y= \pm W$ denotes the positions of the two lateral margins. For this transect, this gives $\bar{F}_{\text {lat }}=33 \mathrm{kPa}$.

Expanding the definition in Eqn (12) of lateral drag as

$$
F_{\text {latx }}=-H \frac{\partial}{\partial y}\left(R_{x y}\right)-R_{x y} \frac{\partial H}{\partial y}
$$

shows that two processes contribute to this resistive term, namely transverse gradients in the shear stress (first term on the right-hand side) and a geometric effect caused by pronounced bed topography. Both terms are shown in Figure 5. The shearing term is positive except close to the right margin, indicating resistance to flow. The geometry 

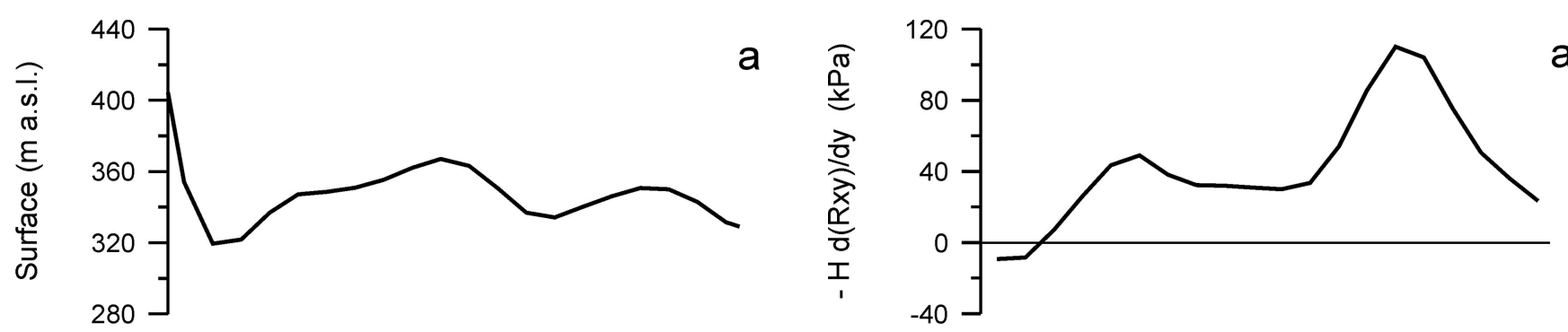

a
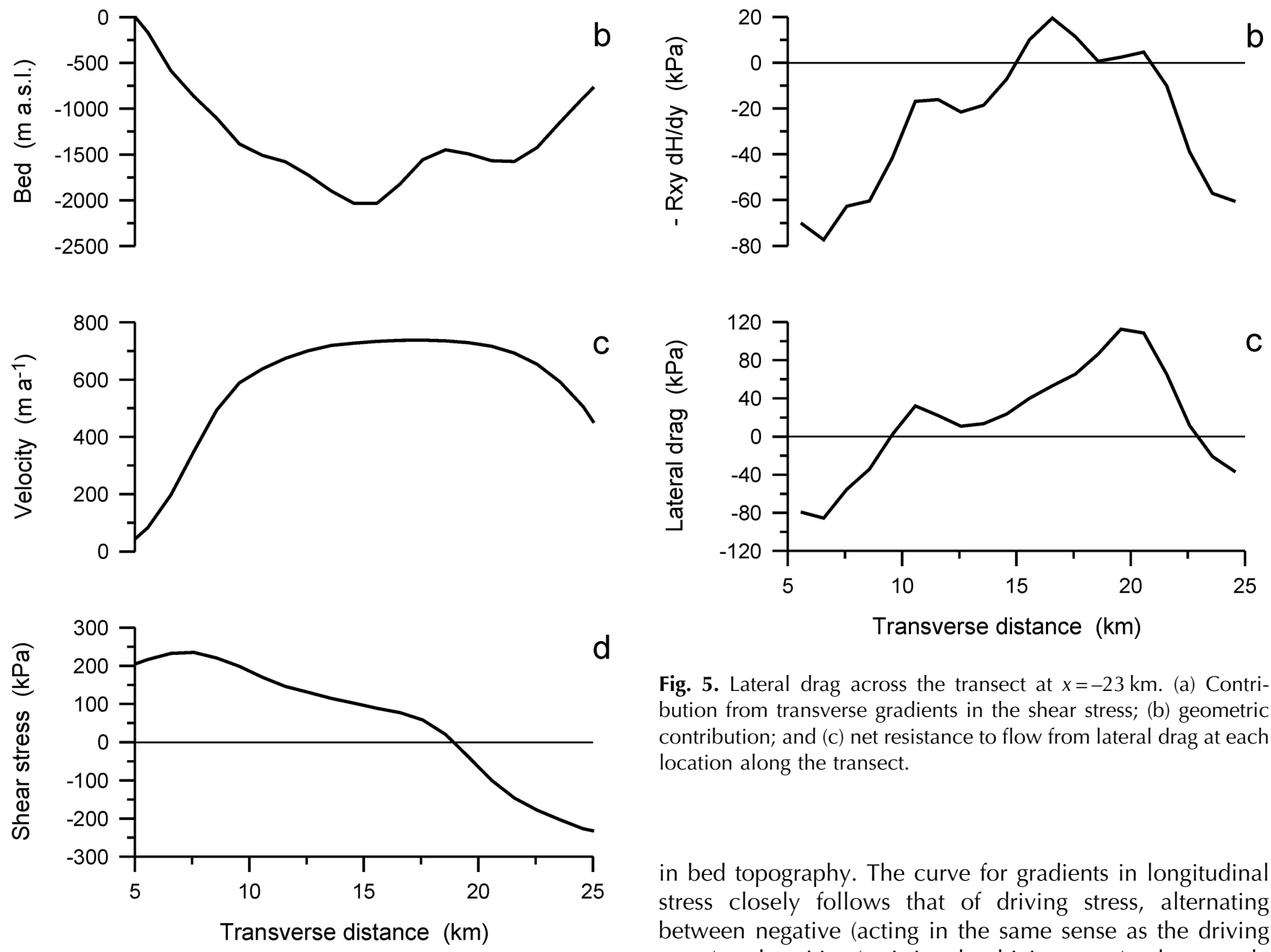

Fig. 5. Lateral drag across the transect at $x=-23 \mathrm{~km}$. (a) Contribution from transverse gradients in the shear stress; (b) geometric contribution; and (c) net resistance to flow from lateral drag at each location along the transect.

Fig. 4. (a) Surface elevation, (b) bed elevation, (c) surface velocity and (d) shear stress, $R_{x y}$, across the transect at $x=-20 \mathrm{~km}$.

term, on the other hand, is mostly negative and thus acting in cooperation with the driving stress. In essence, the thicker ice in the channel is dragging thinner outboard ice along. As a result, the sum of both terms becomes negative close to both margins.

\section{Gradients in longitudinal stress}

The role of gradients in longitudinal stress is limited to small areas where this term counters large variations in driving stress such that basal drag is more uniform (Fig. 3). This becomes apparent when considering force balance averaged over the width of the glacier. Figure 6 shows the widthaveraged geometry and Figure 7 the force-balance terms.

From $x=-28 \mathrm{~km}$ to $x=-23 \mathrm{~km}$ the driving stress varies by $\sim 300 \mathrm{kPa}$ over a distance of $\sim 5 \mathrm{~km}$. At $x>-23 \mathrm{~km}$ the driving stress is near zero, at the down-flow end of a plateau

in bed topography. The curve for gradients in longitudinal stress closely follows that of driving stress, alternating between negative (acting in the same sense as the driving stress) and positive (resisting the driving stress) values, partly compensating for variations in driving stress. Averaged over the length of the lower trunk, however, these positive and negative values largely cancel and longitudinal stress gradients do not contribute greatly to the large-scale balance of forces. Lateral drag decreases slightly in the direction of flow, from $36 \mathrm{kPa}$ at $-42 \mathrm{~km}$ to $27 \mathrm{kPa}$ in the grounding zone $(-10 \mathrm{~km})$ and on average provides $\sim 20 \%$ of flow resistance; the remainder $(\sim 80 \%)$ of flow resistance along the segment is associated with basal drag.

\section{Temporal changes}

To investigate whether the pronounced peaks in driving stress and corresponding variations in basal resistance are stationary or migrating, force balance is evaluated for three additional times (1988, 2006 and 2011). As shown in Figure 8 the minimum in driving stress at $-23 \mathrm{~km}$ increased as the local surface flattened over the period 1978-2011. Otherwise, the pattern of driving stress remained stationary. Given the grid spacing used in the calculations $(1 \mathrm{~km})$, the small shift in basal drag maxima and minima is not very significant. 

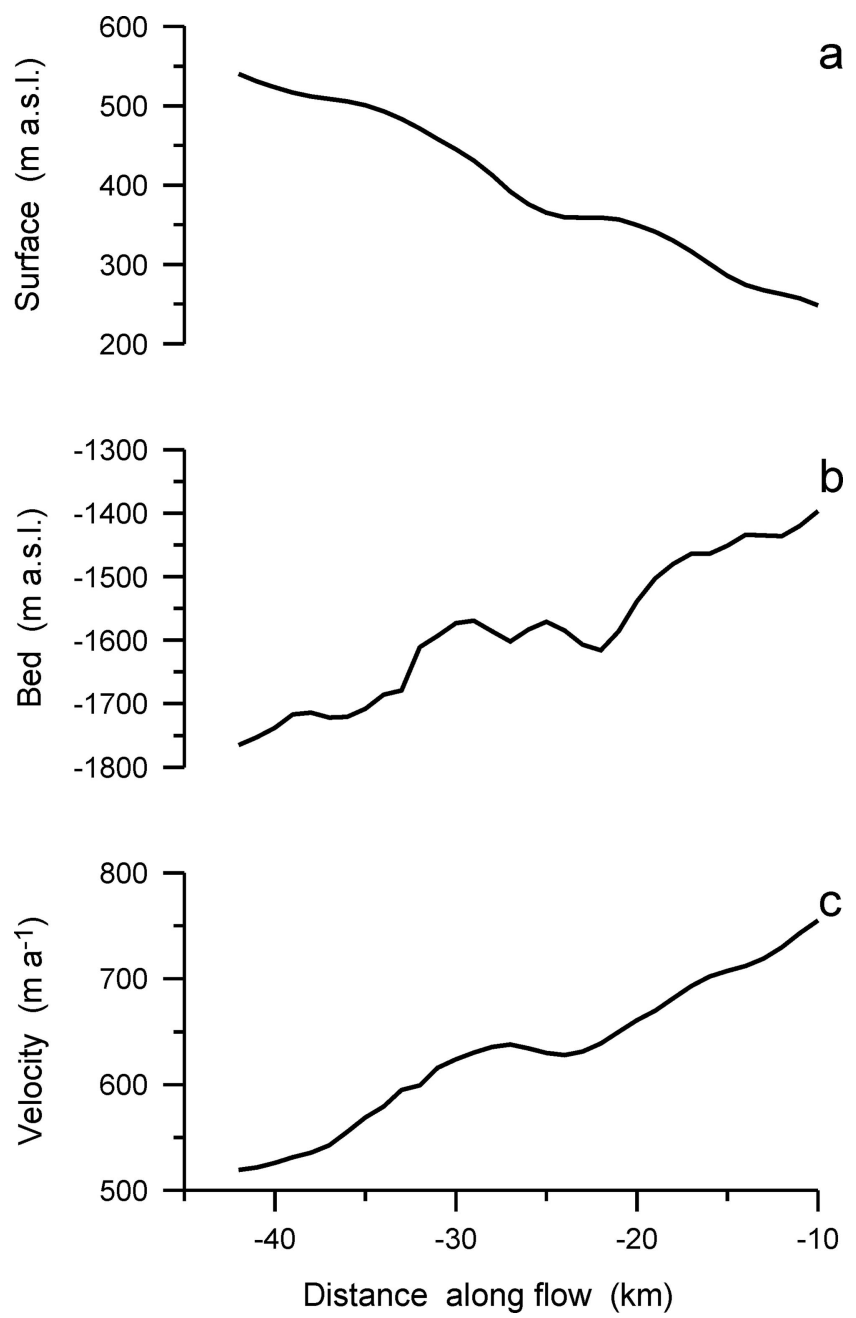

Fig. 6. Width-averaged (a) surface elevation, (b) bed elevation and (c) surface velocity along the trunk of Byrd Glacier.

Reusch and Hughes (2003) propose that the variations in driving stress - which they term surface 'waves' - reflect variations in bed coupling rather than being caused by bed topography. Sergienko and Hindmarsh (2013) observed similar ribbed-like patterns in basal resistance on Pine Island and Thwaites Glaciers, West Antarctica, co-located with local highs and lows in the hydraulic potential gradient, leading these authors to suggest that drainage of subglacial water may control the location and evolution of regions' high basal drag. To explore whether the basal drag variations on Byrd Glacier are similarly related to subglacial water drainage, consider the pressure gradient driving discharge of water under the glacier.

Following Sergienko and Hindmarsh (2013) the hydraulic pressure gradient is calculated from

$$
\nabla \phi=\rho g \nabla\left(H+\frac{\rho_{\mathrm{w}}}{\rho} b\right)
$$

where $b$ represents the elevation of the bed $(b<0$ if below sea level) and $\rho_{w}$ the density of water. The term in parentheses represents the height above buoyancy, and the assumption is made that a full and easy drainage connection to the adjacent ocean exists (Van der Veen, 2013, section 7.4). As shown in Figure 9a, maxima in driving stress coincide with maxima in the hydraulic gradient, supporting the hypothesis that basal drag variations are associated with subglacial drainage. It should be noted,
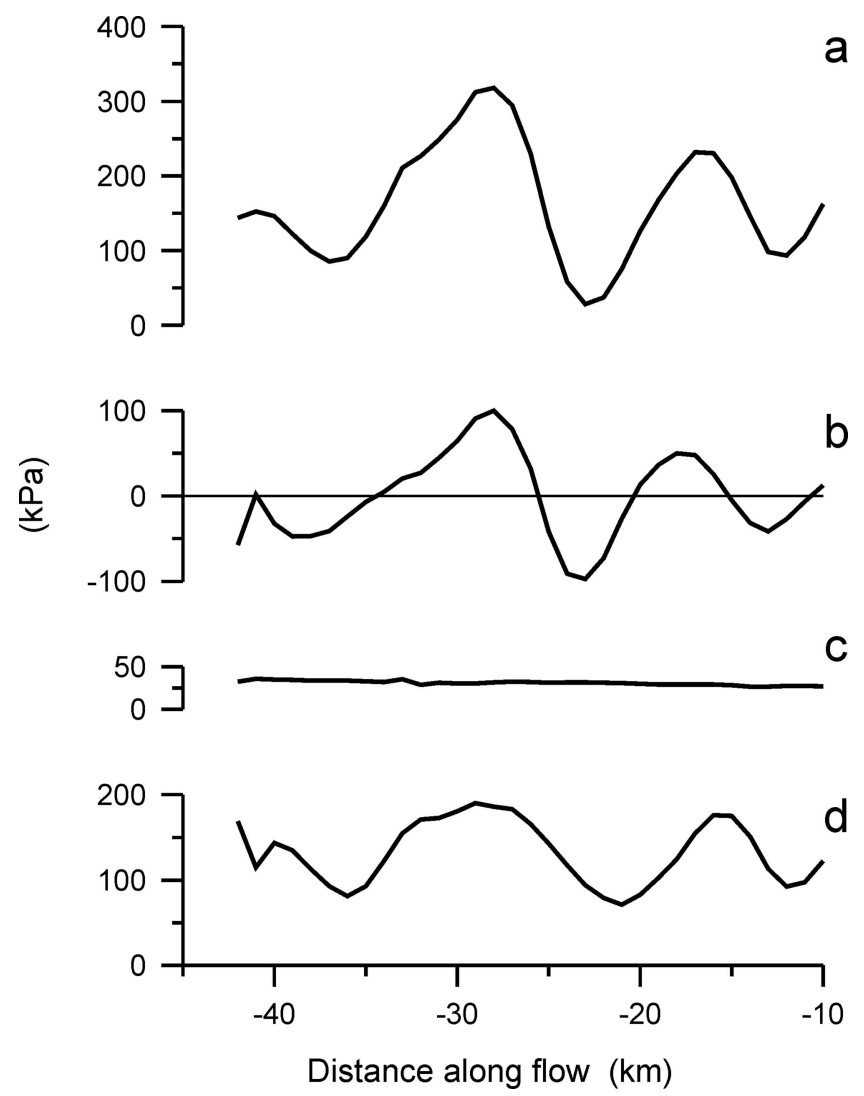

Fig. 7. Terms in the width-averaged along-flow balance of forces: (a) driving stress, (b) gradients in longitudinal stress, (c) lateral drag and (d) basal drag.
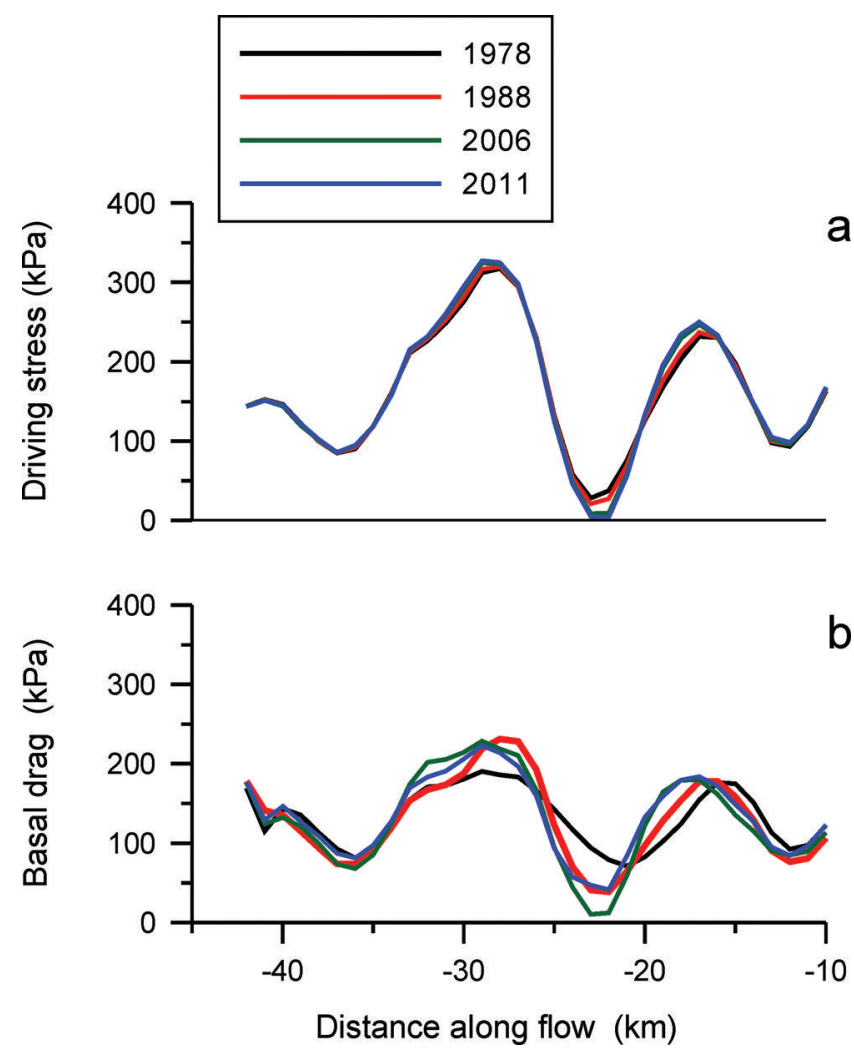

Fig. 8. Width-averaged (a) driving stress and (b) basal drag along the trunk of Byrd Glacier, calculated for four epochs. 

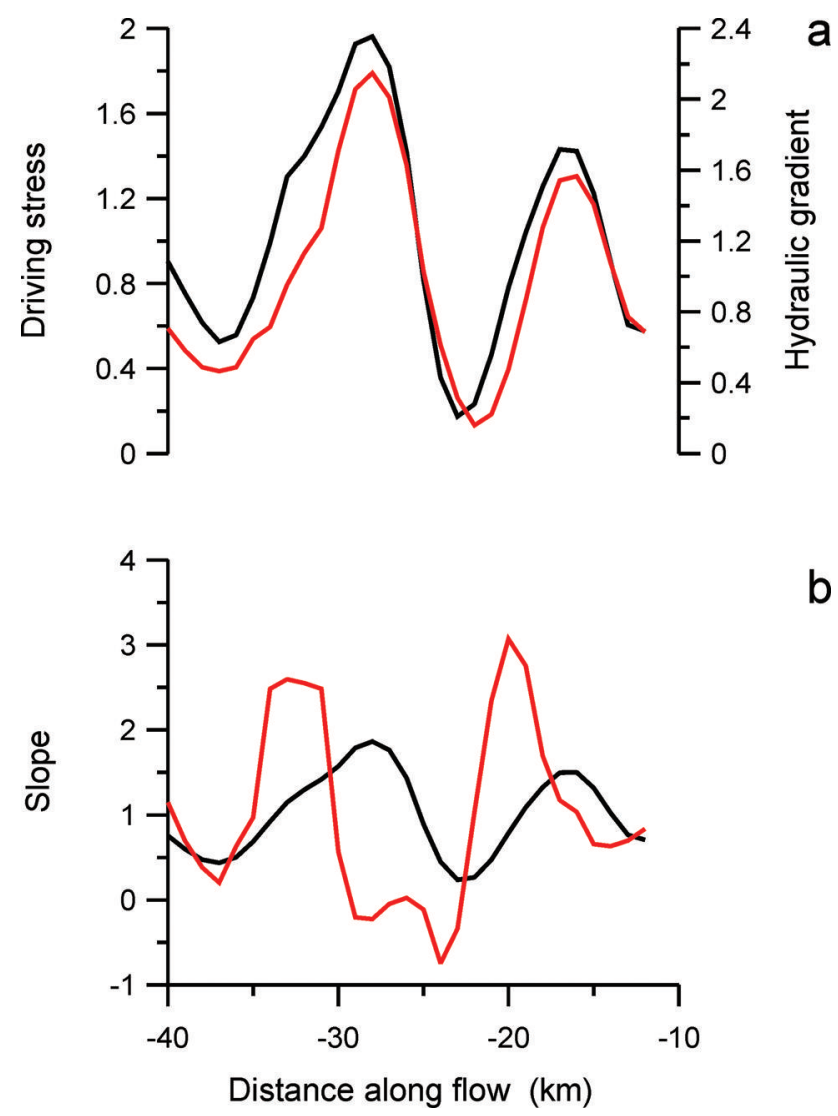

Fig. 9. (a) Width-averaged driving stress (black curve, scale on left) and gradient in hydraulic pressure (red curve, scale on right) along the trunk of Byrd Glacier; both quantities are normalized by dividing by their respective average values. (b) Normalized widthaveraged surface slope (black curve) and bed slope (red curve).

however, that it remains unresolved whether subglacial drainage patterns and associated spatial variations in effective basal pressure are the cause of the pattern in basal resistance, or vice versa.

As noted by Sergienko and Hindmarsh (2013), the colocation of highs and lows in hydraulic potential gradient and in basal resistance was to be expected because the contribution of surface slope to gradient in hydraulic potential is about ten times the contribution associated with bed slope (Shreve, 1972; Cuffey and Paterson, 2010, p. 196). Thus, a high gradient will occur where the driving stress and consequently basal drag - is large, and the spatial commonality between the two patterns may not reflect causality. To investigate whether variations in driving stress are linked to bed topography, Figure 9b shows surface and bed slopes. These graphs suggest that a correlation exists with highs in surface slope displaced several kilometers down-flow of a corresponding peak in bed slope. Regression of the surface slope shifted over $5 \mathrm{~km}$ against the bed slope yields a correlation coefficient $R^{2}=0.51$.

\section{Basal sliding}

In calculating the force-balance terms, the assumption is made that the horizontal resistive stresses, $R_{x x}$ and $R_{x y}$, are constant throughout the ice thickness and can be estimated from surface velocities. This would be correct if all motion was associated with basal sliding, or vertical velocity shear was concentrated in a comparatively shallow basal layer. If
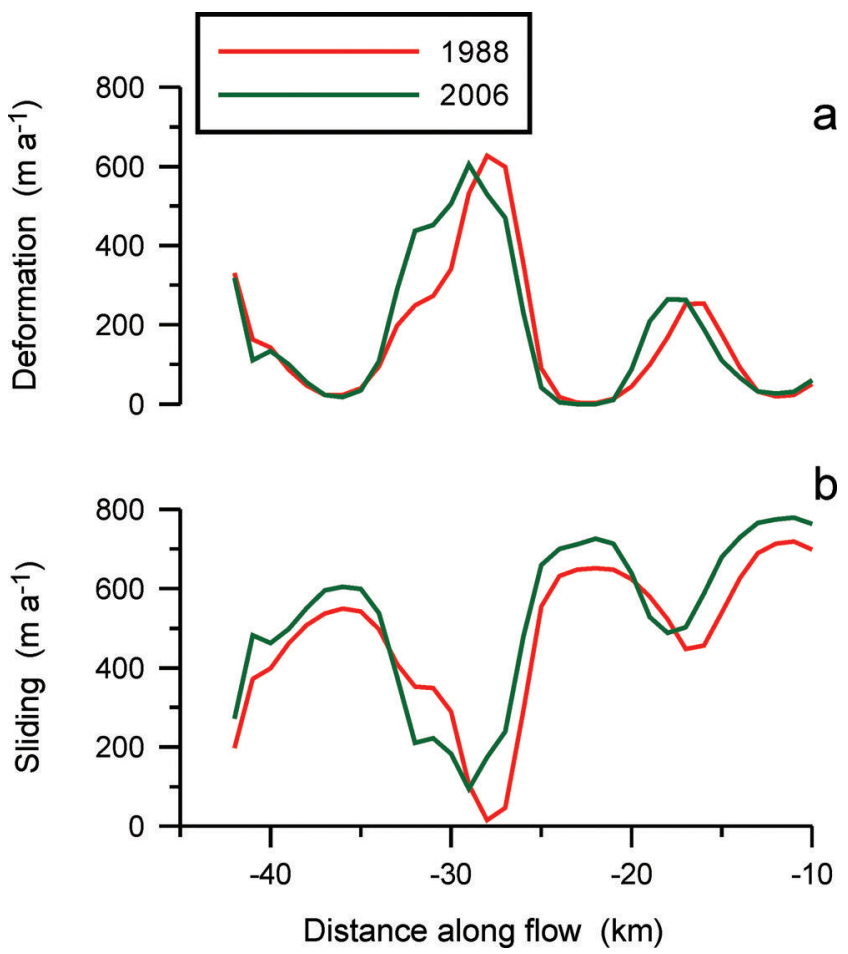

Fig. 10. Partitioning of surface velocity between internal deformation calculated from (a) lamellar-flow theory and (b) basal sliding.

depth variation is important, these stresses will be smaller at depth, and flow resistance associated with gradients in longitudinal stress and lateral drag will be less as well, and basal drag closer to the driving stress. To investigate whether there is significant velocity variation with depth, consider the velocity component due to internal deformation.

In first approximation, the deformational component of velocity can be estimated using the lamellar flow model (Van der Veen, 2013, section 4.2) giving

$$
U_{\text {def }}(h)=\frac{1}{2} H\left(\frac{\tau_{\mathrm{b}}}{B_{\mathrm{d}}}\right)^{3}
$$

for the surface velocity. Because most vertical shear is concentrated in the deeper ice layers, a smaller value corresponding to warmer ice should be used for the viscosity parameter, $B_{\mathrm{d}}$, than used in the force-balance equations. The value $B_{\mathrm{d}}=270 \mathrm{kPaa}^{1 / 3}$ corresponding to a temperature of $\sim-5^{\circ} \mathrm{C}$ is used here, this being the smallest value allowable as dictated by the requirement that the surface speed estimated from Eqn (16) cannot exceed the measured surface speed.

Partitioning of flow between deformation and sliding is shown in Figure 10. As expected, the curve of deformational velocity closely reflects that of basal drag, with maxima at the locations of the sticky spots. Because the observed surface velocity varies smoothly in the flow direction, there are large concomitant spatial variations in the sliding velocity. These large fluctuations in partitioning of sliding and internal deformation seem to be unrealistic and can be significantly reduced by choosing a greater value for $B_{\mathrm{d}}$. For example, $B_{\mathrm{d}}=600 \mathrm{kPa}^{1 / 3}$ yields a maximum deformational velocity of $57 \mathrm{~m} \mathrm{a}^{-1}$ (at $-28 \mathrm{~km}$ ) and almost all discharge is due to basal sliding. Such a large value for the viscosity parameter corresponds to very cold basal ice, which 


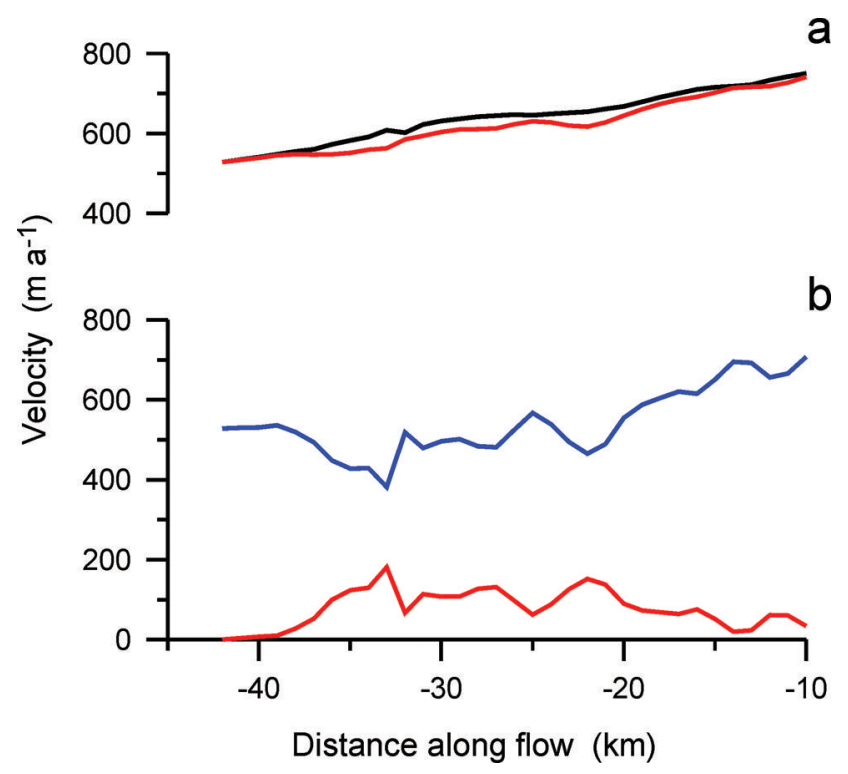

Fig. 11. (a) Measured surface velocity (black curve) and depthaveraged balance velocity (red curve). (b) Depth-averaged deformational velocity (red curve) and sliding velocity (blue curve) inferred from continuity and measured surface velocity.

appears to be irreconcilable with a large sliding component. Nevertheless, continuity considerations also suggest that internal deformation is rather small, even at the locations of large basal drag.

Averaged over the width, $W$, of the glacier, the continuity equation reads

$$
\frac{\partial H}{\partial t}=-\frac{1}{W} \frac{\partial Q}{\partial x}+M,
$$

with $Q=H U W$ the ice flux and $M$ the surface mass balance (Van der Veen, 2013, section 9.4). This equation can be solved for the balance velocity using the width-averaged rates of elevation change from Schenk and others (2005) and $M=-0.25 \mathrm{~m} \mathrm{a}^{-1}$ (Ligtenberg and others, 2014). At the upstream end of the flowline $(x=-42 \mathrm{~km})$ the ice flux is calculated making the assumption that all flow is due to basal sliding and the sliding velocity equals the measured surface speed. Figure 11a shows the measured surface speed (1988) and the depth-averaged balance velocity.

The balance velocity, $\bar{U}_{\text {bal }}$, is the sum of basal sliding, $U_{s}$, and the depth-averaged velocity from internal deformation, $\bar{U}_{\text {def }}$ :

$$
\bar{U}_{\text {bal }}=U_{\mathrm{s}}+\bar{U}_{\text {def }}
$$

For lamellar flow, the depth-averaged velocity equals $4 / 5$ of the surface velocity. Denoting the measured surface velocity as $U_{\mathrm{m}}(h)$, this gives a second equation,

$$
U_{\mathrm{m}}(h)=U_{\mathrm{s}}+\frac{5}{4} \bar{U}_{\text {def }} .
$$

The set of two equations (18) and (19) contains two unknowns and thus can be solved to find the deformational and sliding components of the total ice velocity. The result is shown in Figure 11b and indicates that the deformational component is small compared with the sliding speed. Thus, flow of Byrd Glacier is accommodated mostly by basal sliding. This finding justifies a posteriori neglecting vertical variation in the horizontal resistive stresses in the forcebalance calculations.
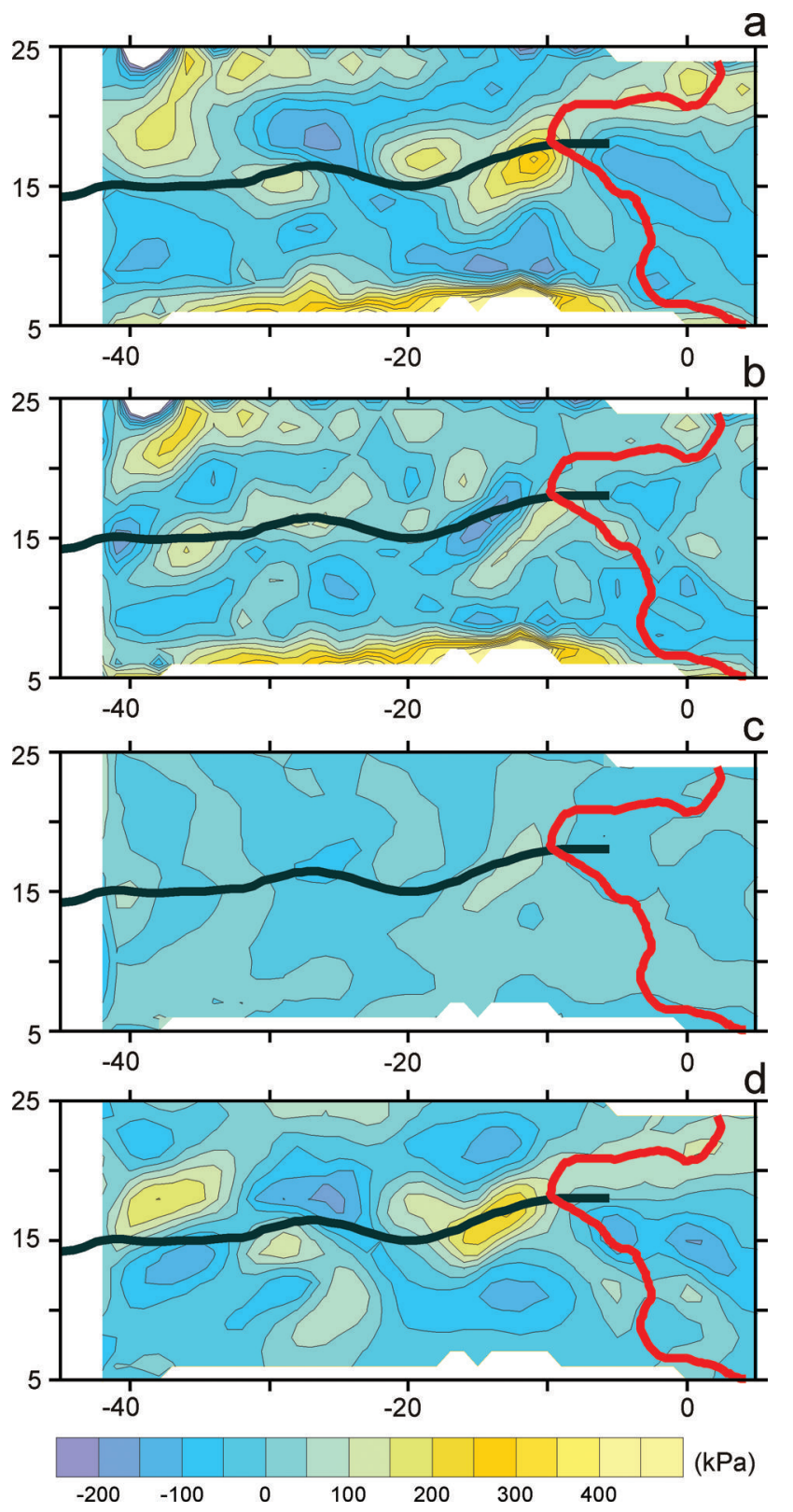

Fig. 12. Terms in the across-flow balance of forces: (a) driving stress, (b) basal drag, (c) lateral drag and (d) gradients in longitudinal stress. Axis labels as in Figure 1.

\section{FORCE BALANCE: ACROSS-FLOW DIRECTION}

Force-balance terms in the local across-flow direction are shown in Figure 12. There is a significant surface slope in the across-flow direction, resulting in regions where the component of basal drag in this direction is nonzero, most notably at the location of the sticky spot upstream of the grounding line identified in Figure $3 \mathrm{~b}$. In the absence of a velocity in this direction (by definition of the local flow-following coordinate system), this result is difficult to understand.

Formally, basal drag is defined to include all basal resistance, and

$$
\tau_{\text {by }}=R_{y z}(b)-R_{y y}(b) \frac{\partial b}{\partial y}-R_{x y}(b) \frac{\partial b}{\partial x},
$$

where $z=b$ denotes the bed elevation (Van der Veen, 2013, p. 49). Thus, it could be that transverse basal drag is induced by basal topography through the form drag terms (last two terms on the right-hand side). This is not the case, however, 


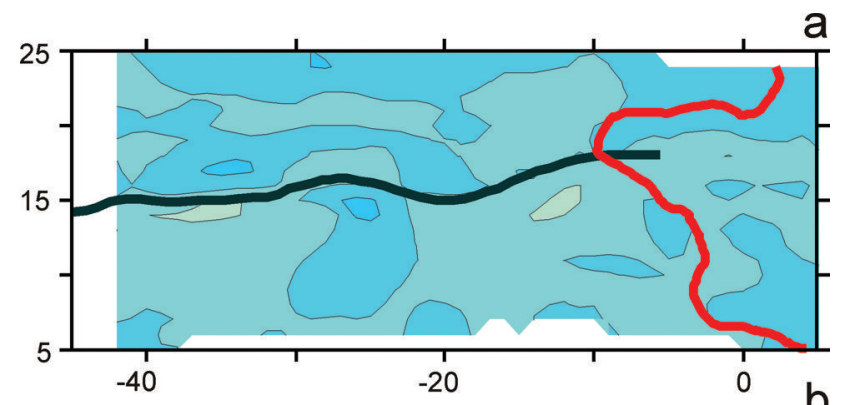

a

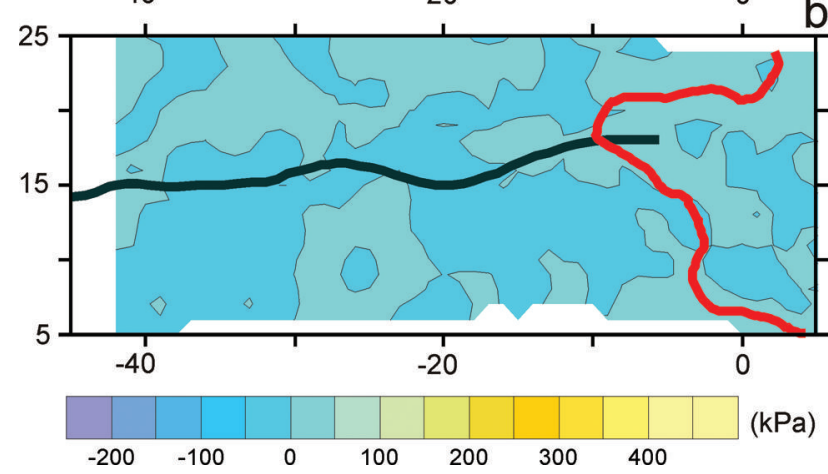

Fig. 13. Contributions to the across-flow component of basal drag associated with (a) transverse bed slope and (b) along-flow bed slope. Axis labels as in Figure 1.

as illustrated in Figure 13, which shows the contributions to the across-flow component of basal drag associated with the transverse and along-flow bed slope. The magnitude of both terms is too small to explain the large inferred values of basal drag shown in Figure 12d.

It could be that the nonzero component of basal drag in the across-flow direction points to spatial variations in ice strength. In the calculations, the viscosity parameter is taken constant on the glacier $\left(B=600 \mathrm{kPaa}^{1 / 3}\right)$. There may be localized regions where the ice is softer or stronger than elsewhere. To be fully correct, investigating this procedure would involve iteratively solving for the viscosity parameter as was done by Larour and others (2005) on the Ronne Ice Shelf. As a start, we seek an enhancement factor that reduces the cross-flow basal drag to near zero, using the results obtained above. This approximation excludes the effect of a spatially varying viscosity parameter on stress gradients but is sufficient for exploratory purposes. For the region of high transverse basal drag just upstream of the grounding line the viscosity parameter is too large by a factor of $\sim 4$ where basal drag is most negative, and too small by a factor of $\sim 2$ where basal drag is most positive.

A counter-argument to the model invoking spatial variations in ice strength is that the anomalous pattern is stationary. Basal drag in the transverse direction is primarily due to corresponding variations in the driving stress. Figure 14 shows maps of the across-flow component of driving stress for three different times covering the period 1988-2011. While there are small variations between the maps, which may be partly attributed to different techniques used to reconstruct the various surface elevation maps, the general pattern remained the same. Over the 33 year interval, the ice near the center moved a distance of $\sim 23 \mathrm{~km}$. It is difficult to comprehend how ice can undergo sequential softening and hardening as it advects downglacier, while the overall pattern of strength variations remains spatially stationary.

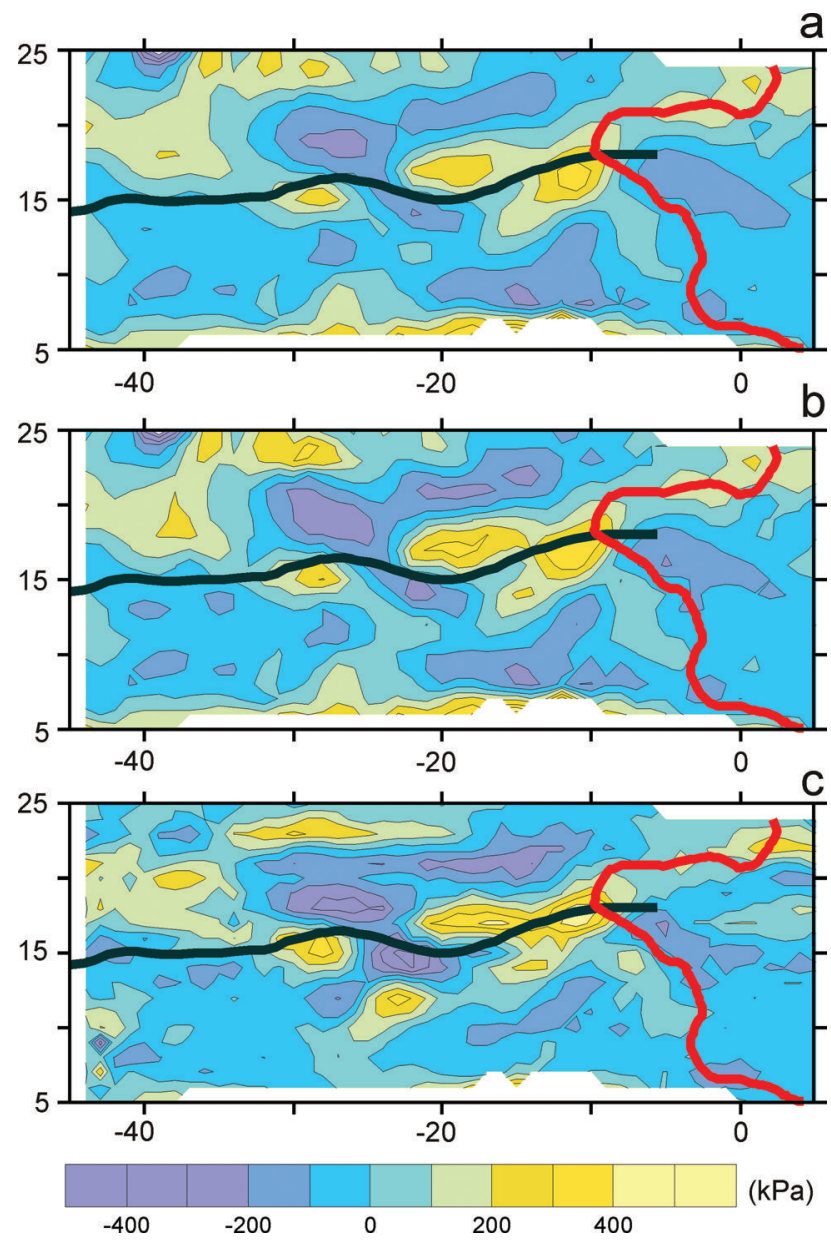

Fig. 14. Across-flow component of driving stress in (a) 1988, (b) 2006 and (c) 2011. Axis labels as in Figure 1.

Based on force-balance calculations that account for vertical variations in ice velocity, Whillans and others (1989) conclude that the isotropic flow law is inadequate as it leads to unreasonable velocities at depth and velocity variations. Constitutive relations other than Glen's flow law have been proposed (Man and Sun, 1987; Goldsby and Kohlstedt, 2001). Changing the exponent in Glen's law to $n=1$ (which in first order approximates the GoldsbyKohlstedt flow law) has no important effect on calculated basal drag, and the general pattern shown in Figures 3 and 12 persists. Similarly, including normal-stress effects in the flow law following the approach adopted by Van der Veen and Whillans (1990) for flow along the Dye-3 strain network has minimal effect on the calculated patterns of basal drag.

Thus, it must be concluded that across-flow variations in driving stress are linked with spatially varying conditions at the glacier bed, either resulting from small-scale topography or from changes in basal slipperiness. This situation is not unique to Byrd Glacier; for example, we find similar smallscale variations on Helheim and Kangerlussuaq glaciers in East Greenland.

\section{DISCUSSION}

The force-balance results obtained in this study raise several interesting questions about the flow of Byrd Glacier. First, the across-flow component of basal drag is perplexing, yet appears not to be an isolated phenomenon; similar patterns are observed on other glaciers. This transverse basal 
resistance is associated with transverse variations in surface elevation, resulting in a significant component of basal drag in that direction. The stationarity of these elevations strongly suggests that these are not caused by spatial variations in ice strength but, rather, are linked to basal conditions.

Hulbe and Whillans (1994) discuss deformation patterns within a $25 \mathrm{~km} \times 10 \mathrm{~km}$ strain grid on Whillans Ice Stream (former Ice Stream B), and surveyed using kinematic GPS. While that study did not include an assessment of forces and, in particular, of basal drag, the map of surface topography shows topographic highs and lows aligned approximately in the direction of flow, resulting in surface slopes in the direction perpendicular to flow. As these authors note, any disturbance in the surface would be expected to relax towards a state of constant gravitational potential, which should be reflected in the patterns of surface strain rates, with tensile horizontal strain rates in the vicinity of topographic highs and more compressive strain rates near topographic valleys. Because the surface features are predominantly in the along-flow direction, surface relaxation should be expressed mostly in the transverse normal strain rates (Hulbe and Whillans, 1994), or, equivalently, lead to gradients in longitudinal stress in the transverse direction. For the strain grid considered, this is not the case, however, and there is a significant topographic residual, i.e. topographic relief that is not relaxing (Hulbe and Whillans, 1994, fig. 4), associated with stationary bed features causing small-scale flow disturbances.

The surface topographic features on Byrd Glacier (as well as on other glaciers) are similar to those described by Hulbe and Whillans (1994) in that they are mostly aligned with the direction of ice flow and of limited extent in the transverse direction. Their stationarity indicates that these features reflect flow disturbances caused by stationary bed features. Hulbe and Whillans (1994) draw an analogy with a submerged boulder in a river: while some of the water will flow over the boulder, most water will be deflected to the sides and converge in the lee of the boulder.

Theory (Reeh, 1987) as well as numerical modeling experiments (Sergienko, 2012) suggest that isolated basal protuberances distort the flow pattern, resulting in transverse elevation variations and velocity perturbations. Investigating this possibility would require high-resolution velocity maps. The spatial resolution of the velocity data available for this study is insufficient to investigate the occurrence of smallscale velocity perturbations on Byrd Glacier. Moreover, the estimated uncertainty in derived velocities ranges from $6 \mathrm{~m} \mathrm{a}^{-1}$ for the InSAR-derived velocities, to $43 \mathrm{~m} \mathrm{a}^{-1}$ for the 1988/89 ASTER-derived velocities. Together, these limitations preclude examination of velocity perturbations on spatial scales smaller than a few kilometers.

Localized flow disturbances could also be associated with regions of the bed with greater than average friction (a 'sandpaper patch': Hulbe and Whillans, 1994). This model is not supported by the results of the force-balance calculations. A scatter plot (not shown here) of the acrossflow component of basal drag against the component in the flow direction does not show any correlation, thus the regions of significant transverse basal resistance do not coincide with locations where the basal resistance in the flow direction is large.

Considering balance of forces in the flow direction, a striking feature is the wave-like pattern in basal drag, caused by variations in the driving stress. This pattern is stationary over the time period considered in this study, and bears close resemblance to the rib-like pattern in basal resistance found by Sergienko and Hindmarsh (2013) on Pine Island and Thwaites Glaciers. Those authors suggest that the ribbing may result from an instability in the coupling between the glacier and its basal environment. In essence, they suggest that these ribs or waves are initiated where coupling between the ice and the bed is low, and the effective basal pressure is low. Over time, the instability evolves, leading to an increased gradient in effective pressure. The difficulty with this model is that, on Byrd Glacier, the pattern of basal drag remained spatially fixed, despite a subglacial flooding event following sudden drainage of two subglacial lakes in the catchment area.

From a mass continuity perspective, variations in the along-flow velocity are readily explained. Referring to Figures 6 and 7, as the ice enters the lower trunk, the bed slopes upward and, to maintain discharge, the velocity must increase. At $x=-30 \mathrm{~km}$, the ice encounters a $10 \mathrm{~km}$-long plateau in bed topography, and the velocity remains level over this distance. Approaching the grounding line, the bed again slopes upward, resulting in a further increase in velocity. These along-flow variations in velocity are achieved through local adjustments in surface slope and driving stress.

Modeling experiments we conducted with a flowband model that includes calculation of gradients in longitudinal stress indicate that highs and lows in driving stress required to maintain flux continuity over an irregular bed topography are balanced locally by gradients in longitudinal stress, such that basal drag remains fairly uniform. On Byrd Glacier, smallscale variations in driving stress are only partially balanced by longitudinal stress gradients, resulting in the wave-like pattern in basal drag. This indicates that there must be spatial variations in basal conditions, such as local fluctuations in effective basal pressure, as suggested by Sergienko and Hindmarsh (2013), or local variations in bed roughness possibly resulting from differential erosion rates. There are insufficient data available to test either of these hypotheses.

Using continuity arguments to estimate the partitioning of ice flow between sliding and internal deformation shows that basal sliding is the main contributor to ice flow. Surprisingly, internal deformation must be relatively small even in the regions where basal drag is large. This suggests that the basal ice must be very stiff with respect to the vertical shear stress. This could indicate a preferred crystalorientation fabric. Alternatively, the basal ice could be debris-laden, although experiments are ambiguous as to how debris content affects the strength of ice (Hooke and others, 1972; Fitzsimons and others, 1999; Iverson and others, 2003; Jacka and others, 2003).

It is tempting to speculate about the stability of the grounding line of Byrd Glacier, especially considering the region of high basal resistance just up-glacier of the grounding line (Fig. 3) and the reverse bed slope (sloping down towards the interior). It is generally accepted that such a geometry is inherently unstable, and a perturbation at the grounding line will result in unstable advance or retreat (Church and others, 2013). The argument is based on massbalance considerations: an increase in ice flux will cause local thinning, resulting in grounding-line retreat into deeper water. Because the ice flux is proportional to the local thickness raised to some power (Schoof, 2007), retreat will cause the discharge flux to increase, resulting in further retreat. Byrd Glacier did not exhibit such behavior following 
the $10 \%$ increase in ice flux between December 2005 and February 2007, in response to drainage of two subglacial lakes in the catchment area (Stearns and others, 2008). Instead, this event appeared to have been short-lived with no consequences for the glacier. Because balance of forces did not change appreciably during the speed-up event (Fig. 8) we surmise that the temporary velocity increase was driven by changes in subglacial drainage and effective basal pressure associated with the sudden influx of lake water. Once the excess water was evacuated, the glacier settled back in its 'normal' flow regime. Gradients in longitudinal stress remained small during flow acceleration, and driving stress at the grounding line continued to be balanced by basal and lateral drags. This scenario is in agreement with the modeling results of Gudmundsson and others (2012) and Gudmundsson (2013), highlighting the stabilizing effect of lateral drag on grounding-line stability.

\section{CONCLUSIONS}

The updated assessment of forces acting on Byrd Glacier presented in this study broadly confirms the earlier results of Whillans and others (1989). Force balance in the along-flow direction shows important variations in driving stress that are partially balanced by gradients in longitudinal stress such that basal drag is more uniform. Nevertheless, there are spatial variations in basal drag ('sticky spots') that are stationary. Averaged over the lower trunk, basal drag provides $\sim 80 \%(130 \mathrm{kPa})$ of flow resistance; lateral drag resists the remaining $20 \%$ (32 $\mathrm{kPa}$ ) of the average driving stress.

Balance of forces in the across-flow direction is more complicated and suggests important small-scale flow disturbances related to either bed topography or variations in bed friction, leading to surface slopes in the transverse direction, although the spatial extent of these slope variations is small $(2-3 \mathrm{~km})$. Observations on other glaciers suggest such topographic features are widespread. Without more detailed modeling, the nature of these flow disturbances cannot be addressed quantitatively, but it appears unlikely that they have an important effect on large-scale flow dynamics of glaciers.

The grounding line of Byrd Glacier is located in a region where the bed slopes upward. Such a configuration is generally believed to be unstable, with small perturbations at the grounding line leading to irreversible retreat of the grounding line. This scenario is not supported by the present results. Despite a $10 \%$ increase in ice discharge between December 2005 and February 2007, following drainage of two subglacial lakes in the catchment area, the position of the grounding line has not retreated significantly and the glacier has decelerated since then. During the speed-up event, partitioning of flow resistance did not change, suggesting the increase in velocity was caused by a temporary decrease in basal effective pressure.

\section{ACKNOWLEDGEMENTS}

This research was supported through US National Science Foundation (NSF) grant ANT-0944597 and NASA grant NNX11AR23G. We acknowledge the use of data and/or data products from CReSIS generated with support from NSF grant ANT-0424589 and NASA grant NNX10AT68G. Comments by Jim Fastook and an anonymous reviewer helped improve the text and figures.

\section{REFERENCES}

Brecher HH (1982) Photographic determination of surface velocities and elevations on Byrd Glacier. Antarct. J. US, 17(5), 79-81

Brecher HH (1986) Surface velocity determination on large polar glaciers by aerial photogrammetry. Ann. Glaciol., 8, 22-26

Brunt KM, Fricker HA, Padman L, Scambos TA and O'Neel S (2010) Mapping the grounding zone of Ross Ice Shelf, Antarctica, using ICESat laser altimetry. Ann. Glaciol., 51(55), 71-79 (doi: 10.3189/172756410791392790)

Carosi R, Giacomini F, Talarico F and Stump E (2007) Geology of the Byrd Glacier Discontinuity (Ross Orogen): new survey data from the Britannia Range, Antarctica. USCS Open File Rep. 2007-1947-SRP-030

Church JA and 13 others (2013) Sea level change. In Stocker TF and 9 others eds. Climate change 2013: the physical science basis. Contributions of Working Group 1 to the Fifth Assessment Report of the Intergovernmental Panel on Climate Change. Cambridge University Press, Cambridge

Cuffey KM and Paterson WSB (2010) The physics of glaciers, 4th edn. Butterworth-Heinemann, Burlington, MA

Fitzsimons SJ, McManus KJ and Lorrain RD (1999) Structure and strength of basal ice and substrate of a dry-based glacier: evidence for substrate deformation at sub-freezing temperatures. Ann. Glaciol., 28, 236-240 (doi: 10.3189/172756499781821878)

Floricioiu D, Jezek K, Baessler M and Abdel Jaber W (2012) Geophysical parameters estimation with TerraSAR-X of outlet glaciers in the Transantarctic Mountains. In International Geoscience and Remote Sensing Symposium (IGARSS 2012), 22-27 July 2012, Munich, Germany. Institute of Electrical and Electronics Engineers, Piscataway, NJ

Gogineni S and 10 others (2014) Bed topography of Jakobshavn Isbræ, Greenland, and Byrd Glacier, Antarctica. J. Glaciol., 60(223), 813-833

Goldsby DL and Kohlstedt DL (2001) Superplastic deformation of ice: experimental observations. J. Geophys. Res., 106(B6), 11 017-11030 (doi: 10.1029/2000JB900336)

Gudmundsson GH (2013) Ice-shelf buttressing and the stability of marine ice sheets. Cryosphere, 7(2), 647-655 (doi: 10.5194/ tc-7-647-2013)

Gudmundsson GH, Krug J, Durand G, Favier L and Gagliardini O (2012) The stability of grounding lines on retrograde slopes. Cryosphere, 6(6), 1497-1505 (doi: 10.5194/tc-6-1497-2012)

Hooke RLeB, Dahlin BB and Kauper MT (1972) Creep of ice containing dispersed fine sand. J. Glaciol., 11(63), 327-336

Hughes TJ (1979) Byrd Glacier. Antarct. J. US, 14(5), 88-91

Hughes TJ and Fastook JL (1981) Byrd Glacier: 1978-1979 field results. Antarct. J. US, 16(5), 86-89

Hulbe CL and Whillans IM (1994) Evaluation of strain rates on Ice Stream B, Antarctica, obtained using GPS phase measurements. Ann. Glaciol., 20, 254-262

Iverson NR and 6 others (2003) Effects of basal debris on glacier flow. Science, 301(5629), 81-84 (doi: 10.1126/science.1083086)

Jacka TH, Donoghue S, Li J, Budd WF and Andersen RM (2003) Laboratory studies of the flow rates of debris-laden ice. Ann. Glaciol., 37, 108-112 (doi: 10.3189/172756403781815537)

Larour E, Rignot E, Joughin I and Aubry D (2005) Rheology of the Ronne Ice Shelf, Antarctica, inferred from satellite radar interferometry data using an inverse control method. Geophys. Res. Lett., 32(5), L05503 (doi: 10.1029/2004GL021693)

Ligtenberg SRM, Lenaerts JTM, Van den Broeke MR and Scambos TA (2014) On the formation of blue ice on Byrd Glacier, Antarctica. J. Glaciol., 60(219), 41-50 (doi: 10.3189/2014JoG13J116)

Lucchitta BK and Ferguson HM (1986) Antarctica: measuring glacier velocity from satellite images. Science, 234(4780), 1105-1108 (doi: 10.1126/science.234.4780.1105)

Man CS and Sun QX (1987) On the significance of normal stress effects in the flow of glaciers. J. Glaciol., 33(115), 268-273

McIntyre NF (1985) The dynamics of ice-sheet outlets. J. Glaciol., 31(108), 99-107 
Reeh N (1987) Steady-state three-dimensional ice flow over an undulating base: first-order theory with linear ice rheology. J. Glaciol., 33(114), 177-185

Reusch D and Hughes TJ (2003) Surface 'waves' on Byrd Glacier, Antarctica. Antarct. Sci., 154(4), 547-555 (doi: 10.1017/ S095410200301664)

Rignot E and Jacobs SS (2002) Rapid bottom melting widespread near Antarctic ice sheet grounding lines. Science, 296(5575), 2020-2023 (doi: 10.1126/science.1070942)

Rignot E, Mouginot J and Scheuchl B (2011) Ice flow of the Antarctic Ice Sheet. Science, 333(6048), 1427-1430 (doi: 10.1126/science.1208336)

Scambos TA, Dutkiewicz MJ, Wilson JC and Bindschadler RA (1992) Application of image cross-correlation to the measurement of glacier velocity using satellite image data. Remote Sens. Environ., 42(3), 177-186 (doi: 10.1016/0034-4257(92)90101-0)

Schenk T, Csatho B, Van der Veen CJ, Brecher H, Ahn Y and Yoon $T$ (2005) Registering imagery to ICESat data for measuring elevation changes on Byrd Glacier, Antarctica. Geophys. Res. Lett., 32(23), L23S05 (doi: 10.1029/2005GL024328

Schoof C (2007) Ice sheet grounding line dynamics: steady states, stability, and hysteresis. J. Geophys Res., 112(F3), F03S28 (doi: 10.1029/2006JF000664)

Scofield JP, Fastook JL and Hughes TJ (1991) Evidence for a frozen bed, Byrd Glacier, Antarctica. J. Geophys. Res., 96(B7), 11 649-11655 (doi: 10.1029/91JB00839)

Sergienko OV (2012) The effects of transverse bed topography variations in ice-flow models. J. Geophys. Res., 117(F3), F03011 (doi: 10.1029/2011JF002203)
Sergienko OV and Hindmarsh RCA (2013) Regular patterns in frictional resistance of ice-stream beds seen by surface data inversion. Science, 342(6162), 1086-1089 (doi: 10.1126/ science.1243903)

Shreve RL (1972) Movement of water in glaciers. J. Glaciol., 11(62), 205-214

Stearns LA (2007) Outlet glacier dynamics in East Greenland and East Antarctica. (PhD thesis, University of Maine)

Stearns LA (2011) Dynamics and mass balance of four large East Antarctic outlet glaciers. Ann. Glaciol., 52(59), 116-126

Stearns LA, Smith BE and Hamilton GS (2008) Increased flow speed on a large East Antarctic outlet glacier caused by subglacial floods. Nature Geosci., 1(8), 827-831 (doi: 10.1038/ ngeo356)

Stump E and 6 others (2004) Correlation of Byrd and Selborne Groups, with implications for the Byrd Glacier discontinuity, central Transantarctic Mountains, Antarctica. N.Z. J. Geol. Geophys., 47(2), 157-171 (doi: 10.1080/00288306.2004.9515045)

Swithinbank CW (1963) Ice movement of valley glaciers flowing into the Ross Ice Shelf, Antarctica. Science, 141(3580), 523-524 (doi: 10.1126/science.141.3580.523)

Truffer M and Echelmeyer KA (2003) Of isbræ and ice streams. Ann. Glaciol., 36, 66-72 (doi: 10.3189/172756403781816347)

Van der Veen CJ (2013) Fundamentals of glacier dynamics, 2nd edn. CRC Press, Boca Raton, FL

Whillans IM, Chen YH, Van der Veen CJ and Hughes TJ (1989) Force budget: III. Application to three-dimensional flow of Byrd Glacier, Antarctica. J. Glaciol., 35(119), 68-80 (doi: 10.3189/ 002214389793701554) 